\title{
Autonomic dysfunction detection by an automatic pupillometer as a non-invasive test in patients recovered from COVID-19
}

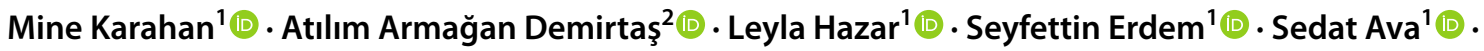 \\ Mehmet Emin Dursun ${ }^{1}$ (1) - Uğur Keklikçi ${ }^{1}$ (1)
}

Received: 7 January 2021 / Revised: 7 March 2021 / Accepted: 19 April 2021 / Published online: 27 April 2021

(c) The Author(s), under exclusive licence to Springer-Verlag GmbH Germany, part of Springer Nature 2021

\begin{abstract}
Purpose To recognize dysfunctions in the autonomic nervous system (ANS) with changes in dynamic and static pupillary responses in patients who recovered from coronavirus disease-2019 (COVID-19)

Methods One month after recovery from COVID-19, patients were subjected to eye examinations. Pupillary responses were measured using a pupillometry system. Dynamic pupil parameters (i.e., pupil contraction amplitude, pupil dilatation latency, pupil contraction latency, pupil dilatation duration, pupil dilatation velocity, pupil contraction duration, pupil contraction velocity, resting pupil diameter [PD]) and static pupil parameters (i.e., mesopic PD, scotopic PD, high photopic PD, and low photopic PD) were registered.

Results Although high photopic and scotopic PDs were significantly higher in patients recovering from COVID-19 than in healthy controls $(P=0.04$ and $P=0.002)$, no statistically significant difference was found in mesopic and low photopic PD $(P=0.19$ and $P=0.41)$. Regarding dynamic pupillometry parameters, resting PD and pupil contraction velocity $(P=0.04$ and $P=0.02$, respectively) were significantly higher in patients recovering from COVID-19 than in healthy controls $(P<0.001$ and $P<0.001$, respectively), whereas pupil dilatation latency and pupil contraction duration were lower in these patients than in healthy controls $(P=0.01$ and $P=0.008$, respectively). No significant differences in pupil contraction amplitude, pupil dilatation duration, pupil contraction latency, and pupil dilatation velocity were found between the study groups $(P=0.93$, $P=0.91, P=0.42$, and $P=0.48$, respectively).

Conclusion Pupil responses, which are controlled by the ANS, were impaired in patients recovering from COVID- 19. Pupillometry shows promise as a non-invasive, easy-to-apply diagnostic technology for detecting autonomic dysfunction in patients recovering from COVID-19.
\end{abstract}

Clinical trial registration Not applicable.

This article is part of a topical collection on Perspectives on COVID-19

\footnotetext{
Atılım Armağan Demirtaş

atilimdemirtas77@gmail.com

1 Department of Ophthalmology, Faculty of Medicine, Dicle

University, Diyarbakır, Turkey

2 Department of Ophthalmology, Izmir Tepecik Training and Research Hospital, Health Sciences University, Izmir, Turkey
} 


\section{Key messages:}

\section{What is known:}

- Studies have shown that patients with COVID-19 develop autonomic dysfunction.

\section{What we found:}

- The results of our study showed that pupil responses, which are controlled by autonomic nervous system, were impaired in patients recovering from COVID-19.

- An automatic pupillometry system can be used as a non-invasive, easy-to-apply diagnostic technology for detecting autonomic dysfunction in patients recovering from COVID-19.

Keywords COVID-19 - Static dynamic pupillometry $\cdot$ Autonomic nervous system

\section{Introduction}

Severe acute respiratory syndrome coronavirus 2 (SARS$\mathrm{CoV}-2)$ is responsible for coronavirus disease-2019 (COVID-19) [1].

COVID-19 causes critical morbidity and mortality with the onset of severe viral pneumonia progressing to acute respiratory distress syndrome and multiorgan system disorder [2]. The most serious consequences have been reported in patients with COVID-19 with diabetes mellitus, hypertension, cerebrovascular disease, and coronary heart disease [3].

Neurological symptoms are common in patients with COVID-19 and may be due to either direct damage to tissues or indirect mechanisms, such as cytokine release. In later stages, severe conditions, such as inflammatory diseases or stroke, can occur. Of 841 patients with COVID-19, 57.4\% developed various neurological symptoms, and neurological complications were the prime reason for death in $4.1 \%$ of the participants. A common feature of the previously described pathogenic coronavirus is neurotropism [4-8].

SARS-CoV-2 can reach the central nervous system through upper nasal passages or circulation. SARS-CoV-2 enters cells via the angiotensin-converting enzyme receptor 2 (ACE2). Endothelium, glial cells, and neurons expressing ACE2 can make these cells potential targets [9].

Pupillary light reflex (PLR) is defined as the constriction and subsequent dilation of the pupil in response to light. It occurs as a result of the antagonistic effects of the iris sphincter and dilator muscles. PLR is under the control of the autonomic nervous system (ANS). Pupil dilation is innervated by the sympathetic nervous system, whereas pupil contraction is innervated by the parasympathetic nervous system. Thus, PLR parameters can be employed as indicators of sympathetic or parasympathetic functions $[10,11]$.
Pupillary responses can be affected by a wide range of disorders. The dynamics of PLR can be affected by parasympathetic stimulation and inhibition, sympathetic stimulation, and neurotransmitter release [12-17].

This study aimed to investigate the detection of autonomic dysfunction by dynamic and static pupillary responses in patients recovering from COVID-19 with the aid of automatic pupillometry.

\section{Materials and methods}

In this study, 60 patients recovering from COVID-19 and 40 healthy controls were examined. The study protocol adhered to the provisions of the Declaration of Helsinki. Approval was obtained from the Ethics Committee (decision date: November 26, 2020, no. 367). Written informed consent was acquired from all patients.

The study included patients with a positive polymerase chain reaction (PCR) test due to COVID-19 and those who exhibited pneumonic infiltration but recovered from treatment. The inclusion criteria were the presence of mild pneumonia and the absence of pulmonary involvement in outpatients. In all patients, PCR and blood tests were performed, computed tomography images were taken, and their treatments were then arranged. Among these patients, those with signs of severe inflammation in blood tests (e.g., low lymphocyte count; high C-reactive protein [CRP], D-dimer, and ferritin levels) were hospitalized, treated, and followedup. All patients were administered with an oral loading dose $(2 \times 1600 \mathrm{mg})$ and a 5 -day maintenance dose $(2 \times 600 \mathrm{mg})$ of favipiravir.

The PCR test of all included patients was negative. Patients whose symptoms and signs improved and showed a negative PCR test were considered cured. Patients who 
recovered from COVID-19 were included in the study after two subsequent negative PCR tests performed at a 1-month interval. One month after recovery from COVID19 , patients underwent eye evaluations by the Department of Ophthalmology. Complete ophthalmological examinations were performed for all patients. Patients with systemic diseases (e.g., diabetes mellitus, and neurological and cardiovascular diseases); with a history of using eye drops and systemic medications; with iris pupil pathology, glaucoma, and pseudoexfoliation; with a cylindrical error of $>1.0$ diopter and a spherical error of $>+3.0$ or $<-3.0$ diopters; and with previous intraocular surgery or inflammatory disease were excluded from the study. The control group consisted of age- and gender-matched individuals who did not have any systemic disease. They had no previous symptoms and were negative for both PCR and antibody tests. Antibody testing of the control group was performed on a Roche Cobas e 601 device (Roche Diagnostics, Germany) with the original kits after two-level quality control. The results obtained from Roche Cobas e 601 was given as reactive or non-reactive and as cutoff values (cutoff index, COI). COI $<1.0$ and non-reactive results are interpreted as negative for anti-SARS-CoV-2 antibodies, and $\mathrm{COI} \geq 1.0$ and reactive results are interpreted as positive for anti-SARS-CoV-2 antibodies. Only one eye of each participant was analyzed to avoid individual variations.

The white blood cell (WBC), neutrophil, lymphocyte, CRP, D-dimer, and ferritin levels of the patients with COVID-19 at disease onset were obtained from hospital records. Reference values for WBC, neutrophil, lymphocyte, CRP, D-dimer, and ferritin were $3.7-10.1 \times 10^{3} / \mu \mathrm{L}$, $1.63-6.96 \times 10^{3} / \mu \mathrm{L}, 1.09-2.99 \times 10^{3} / \mu \mathrm{L}, 0-0.5 \mathrm{mg} / \mathrm{dL}$, $0.08-0.583 \mathrm{mg} / \mathrm{dL}$, and $10-291 \mathrm{ng} / \mathrm{mL}$, respectively.

\section{Pupillometry measurements}

Pupillary measurements were made approximately 1 month after recovery, when the second negative PCR was obtained in the healed patients. In the control group, pupillary measurements were taken immediately after negative PCR and antibody test results were obtained.

Static and dynamic pupillometry measurements were performed by a single clinician. Dynamic and static pupillary responses were measured under different light conditions by using an automatic pupillometry system (MonPack One; Metrovision, Pérenchies, France). Static pupillometry measurements were taken under several illumination levels to measure pupil size in scotopic $\left(0.1 \mathrm{~cd} / \mathrm{m}^{2}\right)$, mesopic $(1 \mathrm{~cd} /$ $\left.\mathrm{m}^{2}\right)$, low photopic $\left(10 \mathrm{~cd} / \mathrm{m}^{2}\right)$, and high photopic $(100 \mathrm{~cd} /$ $\mathrm{m}^{2}$ ) vision conditions.

All measurements were made at similar times, and three consecutive measurements were made. Dynamic pupil parameters (i.e., pupil contraction amplitude, pupil contraction latency, pupil contraction velocity, pupil dilatation latency, pupil dilatation velocity, pupil dilatation duration, pupil contraction duration, resting pupil diameter [PD]) and static pupil parameters (i.e., scotopic PD, high photopic PD, mesopic PD, and low photopic PD) were measured. The average of three measurements was taken and recorded.

\section{Statistical analysis}

SPSS version 26.0 (IBM Corp., Armonk, NY) was used for all statistical analyses. Demographic data were calculated using descriptive statistics. The compatibility of numerical data to normal distribution was tested with the ShapiroWilks test. Relationships between categorical variables were tested with chi-square tests. Continuous variables were compared by independent $t$-tests. The results were evaluated at a 95\% confidence interval and $P<0.05$ significance level.

\section{Results}

Of the 60 patients recovering from COVID-19 in this study, $35(58.3 \%)$ were men, and $25(41.7 \%)$ were women. The control group was composed of 18 $(45.0 \%)$ women and $22(55.0 \%)$ men. The mean age of the patients recovering from COVID-19 was similar to that of the healthy control group $(37.65 \pm 7.06$ years and $37.50 \pm 6.39$ years, $P=0.92$ ). The average ferritin, D-dimer, and CRP levels in patients recovering from COVID-19 were $98.98 \pm 114.30 \mathrm{ng} / \mathrm{mL}, 0.34 \pm 0.24 \mathrm{mg} /$ $\mathrm{dL}$, and $0.85 \pm 1.03 \mathrm{mg} / \mathrm{dL}$, respectively. The average WBC, neutrophil and lymphocyte counts in the patients recovering from COVID-19 were $6.9 \pm 3.40,4.34 \pm 3.20$, and $1.92 \pm 1.05 \times 10^{3} / \mu \mathrm{L}$, respectively (Table 1 ).

Although scotopic and high photopic PDs were significantly higher in patients recovering from COVID-19 than in healthy controls $(P=0.002$ and $P=0.04$, respectively), no statistically significant difference in mesopic and low photopic PD was found $(P=0.19$ and $P=0.41$, respectively) (Table 2 ). Regarding dynamic pupillometry parameters, resting PD and pupil contraction velocity ( $P=0.04$ and $P=0.02$, respectively) were significantly higher in patients recovering from COVID-19 than in healthy controls $(P<0.001$ and $P<0.001$, respectively), whereas pupil dilatation latency and pupil contraction duration were lower in these patients than in healthy controls $(P=0.01$ and $P=0.008$, respectively). No significant differences in pupil contraction amplitude, pupil contraction latency, pupil dilatation duration, and pupil dilatation velocity were found between the study groups ( $P=0.93, P=0.42, P=0.91$, and $P=0.48$, respectively $)$ (Table 3). 

laboratory characteristics of the subjects included in the study
Table 1 Demographic and

\begin{tabular}{llll}
\hline Characteristics & $\begin{array}{l}\text { Patients recovering from } \\
\text { COVID-19 } \\
n=60\end{array}$ & $\begin{array}{l}\text { Healthy control } \\
n=40\end{array}$ & $P$ value \\
\hline Age (years) & $37.65 \pm 7.06$ & $37.50 \pm 6.39$ & $0.92^{*}$ \\
Sex & & & \\
$\quad$ Female & $25(41.7)$ & $18(45.0)$ & $0.66^{\dagger}$ \\
$\quad$ Male & $35(58.3)$ & $22(55.0)$ & \\
Ferritin $(\mathrm{ng} / \mathrm{mL})$ & $98.98 \pm 114.30$ & - & \\
D-dimer $(\mathrm{mg} / \mathrm{L})$ & $0.34 \pm 0.24$ & - & \\
WBC $\left(\times 10^{3} / \mu \mathrm{L}\right)$ & $6.9 \pm 3.40$ & - & \\
Neutrophil $\left(\times 10^{3} / \mu \mathrm{L}\right)$ & $4.34 \pm 3.20$ & - & \\
Lymphocyte $\left(\times 10^{3} / \mu \mathrm{L}\right)$ & $1.92 \pm 1.05$ & - & \\
CRP $(\mathrm{mg} / \mathrm{dL})$ & $0.85 \pm 1.03$ & & \\
\hline
\end{tabular}

Bold values indicate statistically significant $P$ value $(P<0.05)$. Continuous variables were given as mean \pm standard deviation and categorical variables as count (\%)

COVID-19, coronavirus disease-2019; WBC, white blood cell; CRP, C-reactive protein

*Independent $t$-test

${ }^{\dagger}$ Chi-square test

\section{Discussion}

In this study, we aimed to investigate whether ANS dysfunction occurs in patients recovering from COVID-19 through changes in dynamic and static pupillary responses. ANS function can be measured via PLR in various clinical applications [18]. In our study, both static and dynamic pupillometry parameters were impaired in patients recovering from COVID-19.

Postural orthostatic tachycardia syndrome is caused by ANS dysfunction. This syndrome develops after acute stress factors, such as viral illness [19-21]. Therefore, dysautonomia, including postural tachycardia, has been determined in patients with COVID-19 [4, 22].

Some individuals with COVID-19 may develop chronic severe fatigue; cognitive deceleration; autonomic disorders, such as orthostatic intolerance; episodic hyperadrenergic

Table 2 Static pupillometry measurements of the subjects included in the study

\begin{tabular}{llll}
\hline $\begin{array}{l}\text { Pupil diameter (PD) } \\
(\mathrm{mm})\end{array}$ & $\begin{array}{l}\text { Patients recover- } \\
\text { ing from COVID- } \\
19\end{array}$ & $\begin{array}{l}\text { Healthy control } \\
n=40\end{array}$ & $P^{*}$ value \\
& $n=60$ & & \\
\hline Scotopic PD & $4.33 \pm 0.99$ & $3.67 \pm 0.80$ & $\mathbf{0 . 0 0 2}$ \\
Mesopic PD & $3.40 \pm 0.91$ & $3.15 \pm 0.79$ & 0.19 \\
Low photopic PD & $2.97 \pm 0.86$ & $3.11 \pm 0.74$ & 0.41 \\
High photopic PD & $2.71 \pm 0.78$ & $2.47 \pm 0.33$ & $\mathbf{0 . 0 4}$
\end{tabular}

Bold values indicate statistically significant $P$ value $(P<0.05)$. Continuous variables were given as mean \pm standard deviation

COVID-19, coronavirus disease-2019

*Independent $t$-test fluctuations; and exaggerated postural tachycardia. Microangiopathy and endothelial damage are possible mechanisms responsible for dysotonomia in patients with persistent symptoms following COVID-19 [23].

Fatigue appears to be a common manifestation in coronavirus infections, including SARS and Middle East respiratory syndrome, in post-illness stages [24, 25]. Neurally mediated hypotension may be associated with chronic fatigue symptoms [26].

A study revealed that parasympathetic and sympathetic autonomic dysfunctions developed in 50\% of patients 6 months after recovering from SARS. Moreover, 6 of 14 patients recovering from SARS (43\%) had abnormal heart rates during autonomic testing [25].

Cardiovascular complications, such as heart failure, arrhythmias, and myocardial infarction, are common in COVID-19. Sympathetic overactivation affects these conditions more negatively, and sympathoactivation due to comorbidity may increase the morbidity/mortality of patients with COVID-19 [27]. In a previous study, autonomic dysfunction was measured with heart rate variability (HRV), the reduction of which was associated with morbidity and mortality [28].

The increase in angiotensin II caused by COVID-19 in proportion to viral load causes sympathoactivation to worsen in comorbidities. Sympathetic overactivity can have a substantial harmful effect on patients with COVID-19 through its effects on metabolism, heart, lungs, vessels, and/or immune system. ACE1/ACE2 imbalance, cytokine release, or changes in blood gases can further increase sympathetic discharge in COVID-19 [29, 30].

In preclinical testing, vagal nerve stimulation causes the repair of autonomic balance and the reduction of 
Table 3 Dynamic pupillometry measurements of the subjects included in the study

\begin{tabular}{llll}
\hline Characteristics & $\begin{array}{l}\text { Patients recovering from } \\
\text { COVID-19 } \\
n=60\end{array}$ & $\begin{array}{l}\text { Healthy control } \\
n=40\end{array}$ & $P^{*}$ value \\
\hline Resting diameter (mm) & $4.56 \pm 0.0 .96$ & $4.20 \pm 0.49$ & $\mathbf{0 . 0 4}$ \\
Amplitude of pupil contraction (mm) & $1.84 \pm 0.38$ & $1.83 \pm 0.20$ & 0.93 \\
Latency of pupil contraction (ms) & $172.80 \pm 37.56$ & $167.12 \pm 18.72$ & 0.42 \\
Duration of pupil contraction (ms) & $379.43 \pm 100.06$ & $432.15 \pm 59.43$ & $\mathbf{0 . 0 0 8}$ \\
Velocity of pupil contraction & $7.53 \pm 1.55$ & $6.99 \pm 0.75$ & $\mathbf{0 . 0 2}$ \\
Latency of pupil dilatation (ms) & $552.78 \pm 91.89$ & $594.65 \pm 67.52$ & $\mathbf{0 . 0 1}$ \\
Duration of pupil dilatation (ms) & $1719.41 \pm 319.43$ & $1725.37 \pm 109.79$ & 0.91 \\
Velocity of pupil dilatation (mm/s) & $2.96 \pm 0.68$ & $3.04 \pm 0.29$ & 0.48 \\
\hline
\end{tabular}

Bold values indicate statistically significant $P$ value $(P<0.05)$. Continuous variables were given as mean \pm standard deviation

COVID-19, coronavirus disease-2019

*Independent $t$-test proinflammatory cytokine levels in ischemic heart disease [31].

Patients with COVID-19 and parasympathetic deprivation due to comorbidities can experience rapid increases in cytokine release because of the deficiency of functional neuro-vagal anti-inflammatory reflex. In patients with COVID-19, a cytokine storm is assumed to contribute to a rapid pass to a decompensated state [32].

This study has some limitations. The number of patients was low, as they were concerned about disease transmission when they came for examination. In addition, the patients were not followed up in the long term; therefore, we were unable to determine the duration of autonomic dysfunction.

In our study, we observed impaired pupillary responses that reflect autonomic dysfunction in patients recovering from COVID-19. In addition to the effects of autonomic dysfunction on COVID-19 morbidity, automatic pupillometry can be helpful in determining the potential effects of autonomic dysfunction due to COVID-19. Therefore, an automatic pupillometry system can be used as a noninvasive, feasible diagnostic technology for detecting autonomic dysfunction in patients recovering from COVID-19.

\begin{abstract}
Author contribution All authors contributed to the study conception and design. Material preparation, data collection, and analysis were performed by Mine Karahan, Atılım Armağan Demirtaş, Leyla Hazar, Seyfettin Erdem, Sedat Ava, Mehmet Emin Dursun, and Uğur Keklikçi. The first draft of the manuscript was written by Mine Karahan, and all authors commented on previous versions of the manuscript. All authors read and approved the final manuscript.
\end{abstract}

Data availability The authors declare that materials described in the manuscript, including all relevant raw data, will be freely available to any scientist wishing to use them for noncommercial purposes, without breaching participant confidentiality. Moreover, the authors ensure that their datasets are presented in the main manuscript.

\section{Declarations}

Ethics approval All procedures performed in studies involving human participants were in accordance with the ethical standards of the institutional and/or national research committee and with the 1964 Helsinki Declaration and its later amendments or comparable ethical standards. The study was approved by the Ethics Committee of the Medical University of Dicle University, Diyarbakır, Turkey (decision date: November 26, 2020, No. 367).

Consent to participate Informed consent was obtained from all participants.

Consent for publication Additional informed consent was obtained from all participants for whom identifying information is included in this article.

Conflict of interest The authors declare no competing interests.

\section{References}

1. Dong E, Du H, Gardner L (2020) An interactive web-based dashboard to track COVID-19 in real time. Lancet Infect Dis 20(5):533-534. https://doi.org/10.1016/S1473-3099(20)301201 (Erratum.In:Lancet Infect Dis 20(9):e215.DOI:10.1016/ S1473-3099(20)30120-1)

2. Paules CI, Marston HD, Fauci AS (2020) Coronavirus infectionsmore than just the common cold. JAMA 323(8):707-708. https:// doi.org/10.1001/jama.2020.0757

3. Guan WJ, Ni ZY, Hu Y et al (2020) Clinical characteristics of coronavirus disease 2019 in China. N Engl J Med 382(18):17081720. https://doi.org/10.1056/NEJMoa2002032

4. Romero-Sánchez CM, Díaz-Maroto I, Fernández-Díaz E et al (2020) Neurologic manifestations in hospitalized patients with COVID-19: the ALBACOVID registry. Neurology 95(8):e1060 e1070. https://doi.org/10.1212/WNL.0000000000009937

5. Li YC, Bai WZ, Hashikawa T (2020) The neuroinvasive potential of SARS-CoV2 may play a role in the respiratory failure of COVID-19 patients. J Med Virol 92(6):552-555. https://doi.org/ 10.1002/jmv. 25728

6. Yachou Y, El Idrissi A, Belapasov V, AitBenali S (2020) Neuroinvasion, neurotropic, and neuroinflammatory events of 
SARS-CoV-2: understanding the neurological manifestations in COVID-19 patients. Neurol Sci 41(10):2657-2669. https://doi. org/10.1007/s10072-020-04575-3

7. Alam SB, Willows S, Kulka M, Sandhu JK (2020) Severe acute respiratory syndrome coronavirus 2 may be an underappreciated pathogen of the central nervous system. Eur J Neurol 27(11):2348-2360. https://doi.org/10.1111/ene.14442

8. Fehr AR (2015) Perlman S (2015) Coronaviruses: an overview of their replication and pathogenesis. Methods Mol Biol 1282:1-23. https://doi.org/10.1007/978-1-4939-2438-7_1

9. Baig AM, Khaleeq A, Ali U, Syeda H (2020) Evidence of the COVID-19 virus targeting the CNS: tissue distribution, host-virus interaction, and proposed neurotropic mechanisms. ACS Chem Neurosci 11(7):995-998. https://doi.org/10.1021/acschemneuro. 0c00122

10. Fotiou F, Fountoulakis KN, Goulas A, Alexopoulos L, Palikaras A (2000) Automated standardized pupillometry with optical method for purposes of clinical practice and research. Clin Physiol 20(5):336-347. https://doi.org/10.1046/j.1365-2281.2000.00259.x

11. Winn B, Whitaker D, Elliott DB, Phillips NJ (1994) Factors affecting light-adapted pupil size in normal human subjects. Invest Ophthalmol Vis Sci 35(3):1132-1137

12. Adhikari P, Zele AJ, Thomas R, Feigl B (2016) Quadrant field pupillometry detects melanopsin dysfunction in glaucoma suspects and early glaucoma. Sci Rep 6:33373. https://doi.org/10. 1038 /srep33373

13. Rubin LS, Gottheil E, Roberts A, Alterman A, Holstine J (1980) Effects of alcohol on autonomic reactivity in alcoholics. Pupillometric studies. III. J Stud Alcohol 41(7):611-622. https://doi. org/10.15288/jsa.1980.41.611

14. Kardon R, Anderson SC, Damarjian TG, Grace EM, Stone E, Kawasaki A (2011) Chromatic pupillometry in patients with retinitis pigmentosa. Ophthalmology 118(2):376-381. https://doi.org/ 10.1016/j.ophtha.2010.06.033

15. Bär KJ, Boettger MK, Schulz S, Harzendorf C, Agelink MW, Yeragani VK, Chokka P, Voss A (2008) The interaction between pupil function and cardiovascular regulation in patients with acute schizophrenia. Clin Neurophysiol 119(10):2209-2213. https://doi. org/10.1016/j.clinph.2008.06.012

16. Bittner DM, Wieseler I, Wilhelm H, Riepe MW, Müller NG (2014) Repetitive pupil light reflex: potential marker in Alzheimer's disease? J Alzheimers Dis 42(4):1469-1477. https://doi.org/ 10.3233/JAD-140969

17. Giza E, Fotiou D, Bostantjopoulou S, Katsarou Z, Karlovasitou A (2011) Pupil light reflex in Parkinson's disease: evaluation with pupillometry. Int J Neurosci 121(1):37-43. https://doi.org/10. 3109/00207454.2010.526730

18. Hall CA, Chilcott RP (2018) Eyeing up the future of the pupillary light reflex in neurodiagnostics. Diagnostics (Basel) 8(1):19. https://doi.org/10.3390/diagnostics8010019

19. Agarwal AK, Garg R, Ritch A, Sarkar P (2007) Postural orthostatic tachycardia syndrome. Postgrad Med J 83(981):478-480. https://doi.org/10.1136/pgmj.2006.055046
20. Raj SR (2013) Postural tachycardia syndrome (POTS). Circulation 127(23):2336-2342. https://doi.org/10.1161/CIRCULATIO NAHA.112.144501

21. Schondorf R, Low PA (1993) Idiopathic postural orthostatic tachycardia syndrome: an attenuated form of acute pandysautonomia? Neurology 43(1):132-137. https://doi.org/10.1212/wnl. 43.1_part_1.132

22. Umapathi T, Poh MQW, Fan BE, Li KFC, George J, Tan JYL (2020) Acute hyperhidrosis and postural tachycardia in a COVID19 patient. Clin Auton Res 30(6):571-573. https://doi.org/10. 1007/s10286-020-00733-x

23. Miglis MG, Goodman BP, Chémali KR, Stiles L (2021) Re: 'PostCOVID-19 chronic symptoms' by Davido et al. Clin Microbiol Infect 27(3):494. https://doi.org/10.1016/j.cmi.2020.08.028

24. Rogers JP, Chesney E, Oliver D et al (2020) Psychiatric and neuropsychiatric presentations associated with severe coronavirus infections: a systematic review and meta-analysis with comparison to the COVID-19 pandemic. Lancet Psychiatry 7:611-627

25. Lo YL, Leong HN, Hsu LY, Tan TT, Kurup A, Fook-Chong S, Tan BH (2005) Autonomic dysfunction in recovered severe acute respiratory syndrome patients. Can J Neurol Sci 32(2):264

26. Rowe PC, Bou-Holaigah I, Kan JS, Calkins H (1995) Isneurally mediated hypotension an unrecognised cause of chronic fatigue? Lancet 345(8950):623-624. https://doi.org/10.1016/s01406736(95)90525-1

27. Matsushita K, Marchandot B, Jesel L, Ohlmann P, Morel O (2020) Impact of COVID-19 on the cardiovascular system: a review. J Clin Med 9(5):1407. https://doi.org/10.3390/jcm9051407

28. Malik M, Camm AJ (1994) Heart rate variability and clinical cardiology. Br Heart J 71(1):3-6. https://doi.org/10.1136/hrt.71.1.3

29. Liu Y, Yang Y, Zhang C et al (2020) Clinical and biochemical indexes from 2019-nCoV infected patients linked to viral loads and lung injury. Sci China Life Sci 63(3):364-374. https://doi.org/ 10.1007/s11427-020-1643-8

30. Porzionato A, Emmi A, Barbon S, Boscolo-Berto R, Stecco C, Stocco E, Macchi V, De Caro R (2020) Sympathetic activation: a potential link between comorbidities and COVID-19. FEBS J 287(17):3681-3688. https://doi.org/10.1111/febs.15481

31. De Ferrari GM, Stolen C, Tuinenburg AE et al (2017) Long-term vagal stimulation for heart failure: eighteen month results from the NEural Cardiac TherApy foR Heart Failure (NECTAR-HF) trial. Int J Cardiol 244:229-234. https://doi.org/10.1016/j.ijcard. 2017.06.036

32. Del Rio R, Marcus NJ, Inestrosa NC (2020) Potential role of autonomic dysfunction in Covid-19 morbidity and mortality. Front Physiol 11:561749. https://doi.org/10.3389/fphys.2020.561749

Publisher's note Springer Nature remains neutral with regard to jurisdictional claims in published maps and institutional affiliations. 